\title{
Implementasi Kesehatan dan Keselamatan Kerja (K3) bagi Pekerja Lapangan di Pelabuhan New Priok Container Terminal 1
}

\author{
Khoirudin Juniarto $^{1}$, Supartini ${ }^{2 *}$, Vivid Dekanawati ${ }^{3}$, Budi Handojo ${ }^{4}$ \\ ${ }^{1}$ Alumni Sekolah Tinggi Maritim Yogyakarta, Jl. Magelang KM 4.4, Yogyakarta \\ ${ }^{2,3,4}$ Prodi MTL, Sekolah Tinggi Maritim Yogyakarta, Jl. Magelang KM 4.4, Yogyakarta \\ Correponding Author*. E-mail : supartini.amy@gmail.com. Hp: 081578800014
}

\begin{abstract}
Abstrak
Keselamatan dan Kesehatan Kerja (K3) merupakan kebutuhan setiap orang dalam menjalankan pekerjaan dan kegiatan keseharian. Faktor perilaku pekerja yang tidak disiplin, metode kerja kurang tepat, perubahan tempat kerja, peralatan, menjadi penyebab terjadinya kecelakaan kerja. Guna menjamin terlaksananya K3, NPCT1 menerapkan peraturan yang wajib dipatuhi semua pekerja, karyawan maupun tamu yang berkunjung. Dalam penelitian ini, penulis menggunakan metode penelitian kualitatif dengan pendekatan diskriptif. K3 dan keamanan dilakukan sangat ketat dan konsisten sehingga berjalan sesuai ketentukan. K3 dilaksanakan oleh Staf HSSE langsung, jumlah personil 16 (enam belas) orang, terbagi 4 regu dengan kinerja sangat baik dan professional dalam melaksanakan Port Patrol Inspection. NPCT1 memiliki Port Clinic sebagai tempat layanan gangguan kesehatan bagi para pekerja. Port Clinic dijaga oleh 2 (dua) orang dokter dan 4 (empat) paramedis. Dengan persiapan yang matang, pelaksanaan dan pengawasan sangat ketat dan evaluasi secara konsisten dalam penerapan $\mathrm{K} 3$, maka dalam kurun waktu 3 (tiga) tahun berturut turut, mulai 18 Agustus 2016 sampai 18 Agustus 2019, tidak terjadi kecelakaan (Zero Accident), sehingga NPCT1 mendapat apresiasi Penghargaan Kecelakaan Nihil berupa Zero Accident Award dari pengelola Pelabuhan Tanjung Priok.
\end{abstract}

Kata Kunci : K3, Pekerja lapangan.

\begin{abstract}
Occupational Health and Safety (K3) is a necessity for everyone in carrying out work and daily activities. Undisciplined worker behavior factors, inappropriate work methods, changes in workplaces, equipment, causes of work accidents. In order to ensure the implementation of K3, NPCT1 implements regulations that must be obeyed by all workers, employees and visiting guests. In this study, the authors used a qualitative research method with a descriptive approach. Occupational Health and Safety (K3) and security are carried out very strictly and consistently so that it runs according to the stipulations. K3 is carried out by HSSE staff directly, the number of personnel is 16 (sixteen), divided into 4 teams with excellent and professional performance in carrying out Port Patrol Inspection.NPCT1 has a Port Clinic as a health service for workers. Port Clinic is manned by 2 (two) doctors and 4 (four) paramedics. With careful preparation, very strict implementation and supervision and consistent evaluation in the implementation of $\mathrm{K} 3$, then within a period of 3 (three) consecutive years, from 18
\end{abstract}


August 2016 to 18 August 2019, there were no accidents (Zero Accident), so NPCT1 received appreciation of the Zero Accident Award in the form of a Zero Accident Award from the manager of Tanjung Priok Port.

Keywords: K3, Field workers

\section{PENDAHULUAN}

Keselamatan dan Kesehatan Kerja (K3) merupakan kebutuhan setiap orang dalam kegiatan keseharian dan menjalankan pekerjaan. K3 secara umum di Indonesia masih sering terabaikan, perlindungan bagi para pekerja terbilang rendah, walaupun sebagian perusahaan sudah menerapkan system keselamatan kerja bagi karyawan, namun sebagian besar masih belum memenuhi standar keselamatan kerja. (Roqib Muhammad, 2008).

Salah satu contoh kecelakaan kerja di pelabuhan Tanjung Priok, terjadi beberapa kali di PT JICT. Berdasarkan data, di JICT dalam 14 bulan terjadi kecelakaan kerja tragis yang merenggut nyawa 3 orang pekerja. (KPonline Jakarta).

Contoh kecelakaan terjadi Dua kali dalam sehari di tahun 2018 lihat table 1.

Tabel 1. Daftar Kecelakaan.

\begin{tabular}{ccl}
\hline No. & Waktu & \multicolumn{1}{c}{ Kejadian } \\
\hline 1 & $4 / 12 / 2018$ Jam 09.12 & Operator alat Rubber Tyred Gantry Crane (RTGC ) \\
& no. 50 menaruh petikemas dari lapangan penumpukan \\
& ke atas casis truk, namun petikemas yang ditaruh \\
& salah sehingga harus diletakkan kembali. \\
& Pada saat menaruh, alat angkat (spreader) tersangkut \\
& pada petikemas lain, sehingga terjadi senggolan yang \\
& tidak dapat dihindarkan, akibatnya petikemas di blok \\
& penumpukan tersebut saling berjatuhan. \\
\hline 2 & Kejadian yang serupa terjadi lagi pada saat RTGC \\
& melayani muatan ekspor, alat angkat (spreader) \\
& tersangkut pada petikemas dan terjadi benturan \\
& sehingga petikemas di blok penumpukan terjatuh.
\end{tabular}

K3 merupakan salah satu bentuk upaya menciptakan tempat kerja yang aman, sehat, bebas pencemaran lingkungan, sehingga melindungi dan terhindar dari kecelakaan kerja. Tujuannya meningkatkan efisiensi dan meningkatkan produktivitas kerja. Kecelakaan kerja tidak hanya menimbulkan korban jiwa tetapi kerugian materi bagi pekerja dan pengusaha. (Irzal, 2016).

Dari faktor penyebab kecelakaan kerja, menunjukkan bahwa kecelakaan kerja terjadi umumnya disebabkan oleh kesalahan manusia (human error).

Ketersediaan fasilitas keselamatan kerja, dapat menekan kemungkinan terjadinya kecelakaan kerja. Untuk itu penting bagi perusahaan berkomitmen dalam implementasi K3 dan menyediakan fasilitas K3 yang memadai serta sosialisasi kepada para pekerja perusahaan. 
K3 merupakan modal penting bagi perusahaan, karena risiko kecelakaan kerja bongkar muat di pelabuhan merupakan risiko terhadap pelayanan kegiatan bongkar muat dan pelayaran suatu kesatuan sistem dari angkutan di perairan, kepelabuhanan, keselamatan dan keamanan, serta perlindungan lingkungan maritime (Peraturan Pemerintah Republik Indosesia No. 21 Tahun 2010 Tentang Perlindungan Lingkungan Maritim, n.d.)

\section{KAJIAN LITERATUR}

Bekerja dalam dunia industri memiliki resiko tinggi, ada kemungkinan terjadinya kecelakaan dalam setiap kegiatan kerja karena berbagai sebab. (Suma'mur, 1981) Usaha industry pelayaran dan usaha lain di pelabuhan memiliki resiko tinggi dan biaya tinggi, untuk itu salah satu usaha agar berjalan lancar, efektif dan efisien, para pengusaha selalu memperhatikan tentang K3 untuk para pekerja/karyawannya.

Kondisi lingkungan kerja yang tidak baik atau kondisi peralatan kerja yang berbahaya (unsafe condition), dipengaruhi oleh hal hal seperti alat alat yang tidak layak pakai dan alat pengaman yang kurang memenuhi standar. Kedua hal tersebut mencerminkan bahwa perilaku manusia merupakan penyebab utama terjadinya kecelakaan di tempat kerja. (Irzal, 2016).

Dalam Implementasi Keselamatan dan Kesehatan Kerja (K3) bagi Pekerja di pelabuhan memperhatikan regulasi yang berlaku seperti :

\section{A. Dasar Hukum Keselamatan dan Kesehatan Kerja (K3).}

K3 merupakan suatu kondisi dalam pekerjaan yang sehat dan aman baik bagi pekerja, perusahaan maupun masyarakat dan lingkungan. K3 merupakan suatu usaha guna mencegah setiap perbuatan atau kondisi tidak selamat, yang dapat mengakibatkan kecelakaan.

Dasar hukum sebagai acuan terkait K3 meliputi:

1. Undang Undang No. 1 Tahun 1970, Tentang Keselamatan Kerja

2. PP. No. 50 Tahun 2012 Tentang Penerapan Sistem Manajemen K3 (SMK3) menetapkan bahwa setiap perusahaan sebagaimana yang disebut di bawah ini wajib menerapkan SMK3 di perusahaan al:

a. Perusahaan yang mempekerjakan paling sedikit 100 (seratus) orang;

b. Perusahaan yang mempunyai tingkat potensi bahaya tinggi.

c. Penerapan SMK3 memperhatikan ketentuan peraturan perundang-undangan serta konvensi atau standar internasional.

3. Permenaker No 4 Tahun 1987 Tentang Panitia Pembina Keselamatan dan Kesehatan Kerja (P2K3), menetapkan bahwa setiap perusahaan di bawah ini wajib membentuk P2K3:

a. Tempat kerja dimana pengusaha atau pengurus memperkerjakan 100 (seratus) orang atau lebih.

b. Tempat kerja dimana pengusaha memperkerjakan kurang dari 100 (seratus) orang tetapi menggunakan bahan, proses dan instalasi yang memiliki risiko besar terjadinya peledakan, kebakaran, keracunan dan pencemaran radioaktif.

4. Undang-Undang No. 13 Tahun 2003, Tentang Ketenagakerjaan, n.d. . 


\section{B. Sistim Manajemen Keselamatan dan Kesehatan Kerja (SMK3)}

1. ILO - OSH : 2001 (Occupational Safety and Health Management Systems 2001).

ILO-OSH 2001 Occupational Safety and Health Management Systems merupakan standar Internasional yang dikeluarkan oleh PBB (Perserikatan Bangsa-Bangsa), diterbitkan menggunakan Sistem Manajemen Keselamatan dan Kesehatan Kerja secara nasional.

2. Sistem Manajemen Keselamatan Dan Kesehatan Kerja, 2007 (Occupational Health and Safety Assessment Series 18001 : 2007)

K3 merupakan semua kondisi dan faktor yang berdampak pada keselamatan dan kesehatan kerja dari tenaga kerja maupun (kontraktor, pemasok, pengunjung dan tamu) di tempat kerja. Standar (Sistem Manajemen Keselamatan Dan Kesehatan Kerja, 2007), yaitu Sistem Manajemen K3 yang merupakan standar internasional guna pembangunan dan penerapan Sistem Manajemen K3 di setiap organisasi perusahaan di tempat kerja.

\section{Kecelakaan Kerja/Accident}

Kecelakaan kerja memiliki beberapa klasifikasi antara lain:

\section{Klasifikasi Kecelakaan Kerja}

Sistem Manajemen Keselamatan Dan Kesehatan Kerja, 2007 menyatakan bahwa kecelakaan kerja didefinisikan sebagai kejadian yang berhubungan dengan pekerjaan yang dapat menyebabkan cidera atau kesakitan (tergantung dari keparahannya), kejadian kematian, atau kejadian yang dapat menyebabkan kematian.

Menurut (Standard, 1990), Kecelakaan atau accident adalah suatu proses atau keadaan yang mengakibatkan kejadian cidera atau penyakit akibat kerja.

\section{Faktor Penyebab Kecelakaan Kerja}

Adapun penyebab tingginya angka kecelakaan ditempat kerja di dalam (Sistem Manajemen Keselamatan Dan Kesehatan Kerja, 2007) ada dua hal yaitu :

a. Unsafe Condition

Kondisi yang tidak aman dan berbahaya bagi para pekerja, seperti:

1) Tempat kerja yang tidak memenuhi standar / syarat.

2) Alat Pelindung Diri yang tidak sesuai dengan standar yang telah di tetapkan.

3) Kebisingan di tempat kerja.

4) Waktu kerja atau jam terbang yang berlebihan.

5) Perlakukan yang tidak menyenangkan dari atasan.

b. Unsafe Action

Tindakan yang tidak aman dan berbahaya bagi para pekerja, seperti:

1) Adanya percampuran bahan-bahan kimia.

2) Membuang sampah sembarangan.

3) Bekerja sambil bercanda dan bersenda gurau.

4) Mengerjakan pekerjaan yang tidak sesuai dengan skill/keterampilan.

5) Tidak melaksanakan prosedur kerja dengan baik. 


\section{Bahaya/Hazard}

Menurut Sistem Manajemen Keselamatan Dan Kesehatan Kerja, 2007, bahaya merupakan segala kondisi yang dapat merugikan baik cidera, kerugian lain, atau bahaya situasi, tindakan yang berpotensi menciderai manusia, sakit karena penyakit atau kombinasi dari semuanya.

Bahaya tidak dapat diukur, tidak bisa diperkirakan atau sulit diatur. efek yang ditimbulkan dari bahaya tersebut sangat merugikan sehingga dalam bertindak harus berhati-hati serta memperhatikan berbagai rambu larangan yang ada.

\section{Kecelakaan (Accident)}

Menurut Sistem Manajemen Keselamatan Dan Kesehatan Kerja, 2007, accident adalah kejadian yang terkait pekerjaan, dimana suatu cidera, sakit atau kematian terjadi. Sakit merupakan kondisi kelainan fisik, mental yang teridentifikasi berasal dari dan/atau bertambah buruk karena kegiatan kerja dan/atau situasi yang terkait pekerjaan.

\section{Kejadian (Insident)}

Menurut (Antão et al., 2016), kejadian atau incident adalah kejadian yang merupakan hasil dari serangkaian kejadian yang tidak direncanakan/tidak diinginkan/tetapi masih dapat dikendalikan dan tidak menimbulkan kerugian, baik materi maupun non materi baik yang menimpa diri manusia, benda fisik berupa kekayaan atau aset, lingkungan hidup dan masyarakat luas.

\section{Hampir Celaka (Near Miss)}

Menurut (Antão et al., 2016), Near miss, kondisi atau situasi dimana kecelakaan hampir terjadi. Secara sederhana dapat diterjemahkan menjadi "hampir celaka". Near miss ini masuk dalam insident yang dapat dikendalikan.

\section{E. Risiko/Risk}

Menurut (Antão et al., 2016), risiko adalah akibat atau konsekuensi yang dapat terjadi akibat sebuah proses yang sedang berlangsung atau kejadian yang akan datang. Dalam bidang asuransi, risiko dapat diartikan sebagai suatu keadaan ketidakpastian, dimana jika terjadi suatu keadaan yang tidak dikehendaki dapat menimbulkan suatu kerugian.

Sertifikasi Sistem Manajemen Keselamatan Dan Kesehatan Kerja, 2007 diperlukan oleh perusahaan internasional untuk memastikan bahwa mereka memiliki manajemen K3 yang baik. Risiko tersebut terjadi karena perilaku manusia, infrastruktur, dan faktor alat kerja, seperti yang ditunjukkan pada diagram tulang ikan. Sebagian besar risiko keselamatan termasuk dalam kategori risiko rendah dan dapat ditangani melalui kontrol administratif dan penggunaan alat pelindung diri (APD).

Beberapa risiko keselamatan termasuk dalam kategori risiko sedang dan perlu ditangani melalui kontrol teknik dan penggunaan APD.

\section{Penilaian Risiko}

Menurut (Levy \& Wegman, 2000) menyebutkan penilaian risiko atau risk assessment adalah penilaian suatu risiko dengan cara membandingkan terhadap tingkat atau kriteria risiko yang telah ditetapkan. 


\section{Pengendalian Risiko}

Menurut (Levy \& Wegman, 2000) bahwa pengendalian risiko (risk control), suatu tindakan untuk menyelamatkan perusahaan dari kerugian. Pengendalian Risiko dilakukan terhadap seluruh bahaya yang ditemukan dalam proses identifikasi bahaya dan mempertimbangkan tingkat risiko untuk menentukan prioritas dan cara pengendaliannya.

\section{Alat Perlindungan Diri (APD)/Personal Protective Equipment (PPE)}

APD merupakan kelengkapan yang wajib digunakan saat bekerja sesuai bahaya dan risiko kerja guna menjaga keselamatan pekerja dan orang di sekitarnya.

Peraturan Menteri Tenaga Kerja dan Transmigrasi No. Per.08/Men/VII/2010 tentang pelindung diri, yang terdiri:

a.Helm Keselamatan (Safety Helmet)

b.Sepatu Boot (BootShoes)

c.Sepatu pelindung (Safety Shoes)

d.Sarung TanganPelindung (Safety Gloves)

e. Tali Pengaman pada Badan (Full Body Safety Harness)

f. Penutup Telinga (Ear Plug / Ear Muff)

g.Kaca Mata Pengaman (Safety Glasses)

h.Masker (Respirator)

i. Pelindung wajah (Face Shield)

j. Jas Hujan (Rain Coat)

\section{F. Pekerja Lapangan Di Pelabuhan.}

Menurut Sedjun (Manulang, 1987), pekerja lapangan adalah setiap orang yang melakukan pekerjaan, menghasilkan barang atau jasa untuk memenuhi kebutuhan masyarakat, dan melakukan pengukuran langsung di lapangan.

Pekerja lapangan di pelabuhan adalah pekerja yang mempunyai peranan menunjang kegiatan di pelabuhan salah satunya kegiatan bongkar muat. Di pelabuhan banyak macam ragam jenis pekerjaan, pekerjaan yang menuntut mereka selalu siap bekerja 24 jam.

Beberapa pekerja tersebut antara lain:

1. Petugas Mooring.

2. Supir Angkutan.

3. Operator Alat Berat

4. Petugas Kebersihan

5. Petugas Penyedia Makan dan Minum untuk Tenaga Kerja Bongkar Muat

\section{METODE PENELITIAN}

\section{Waktu Dan Tempat Penelitian.}

Pelaksanaan penelitian pada bulan Juni- Agustus 2019 bertempat di New Priok Container Terminal 1 (NPCT1) Tanjung Priok.

Methode penelitian yang digunakan penulis adalah kualitatif dengan motode deskriptif. (Bogdan dkk. dalam Moleong, 2005).

Penelitian deskriptif bertujuan, pertama mengetahui perkembangan sarana fisik tertentu atau frekuensi terjadinya suatu aspek fenomena sosial tertentu; tujuan kedua untuk mendeskripsikan secara terperinci fenomena sosial tertentu. (Singarimbun dan Effendi, 1983). 
Menurut (Mardalis, 2010) Interview merupakan teknik pengumpulan data yang digunakan peneliti untuk mendapatkan keterangan-keterangan lisan melalui bercakap-cakap dan berhadapan muka dengan orang yang dapat memberikan keterangan kepada peneliti. Wawancara dilakukan kepada manajer HSSE dan staf serta pekerja lapangan.

Metode observasi (pengamatan), merupakan hasil perbuatan jiwa secara aktif dan penuh perhatian untuk menyadari adanya sesuatu rangsangan tertentu yang diinginkan, atau suatu studi yang disengaja dan sistematis tentang keadaan atau fenomena sosial dan gejala-gejala psikis dengan jalan mengamati dan mencatat. (Mardalis, 2010). Pengamatan langsung di lapangan melihat kegiatan dan mendokumentasikan melalui foto. Dari hasil penelitian, penulis menyampaikan gambaran implementasi K3, dengan memaparkan layout dan denah lintasan pekerja.

Metode analisa data dilakukan secara deskriptif dimana penulis memperoleh data yang jelas, data-data dipercaya dari suatu sumber, dengan cara menyusun mencocokan apa yang ada dengan keadaan sebenarnya di lapangan. (Narbuko, 2005).

\section{PEMBAHASAN}

Dalam pembahasan dari hasil penelitian, penulis memaparkan implementasi K3 oleh NPCT1 untuk pekerja lapangan.

Guna menjamin terlaksananya K3, NPCT1 menerapkan peraturan yang wajib dipatuhi semua pekerja dan karyawan maupun tamu yang berkunjung.

Karena ketertiban, ketat dan konsisten dalam penerapan K3, dalam kurun waktu 3 (tiga) tahun mulai dari 18 Agustus 2016 sampai 18 Agustus 2019, tidak terjadi kecelakaan (Zero Accident), sehingga pihak Port Authority Tanjung Priok memberikan apresiasi Penghargaan Kecelakaan Nihil berupa Zero Accident Award kepada NPCT1.

Dari hasil penelitian, penulis menyampaikan gambaran implementasi K3, dengan memaparkan layout dan denah lintasan pekerja sebagai berikut:

\section{A. Layout Bagi Pekerja Lapangan Di Terminal NPCT1}

Layout bagi pekerja lapangan ini penulis gambarkan sesuai kondisi di terminal, dimana setiap pekerja dan pengunjung/tamu tidak diperbolehkan berjalan kaki di area container yard, perusahaan memberikan fasilitas shuttle bus/hiace untuk menuju ke area kerja masing-masing. Berikut gambaran kondisi area kerja di terminal dapat dilihat pada gambar di bawah ini: 


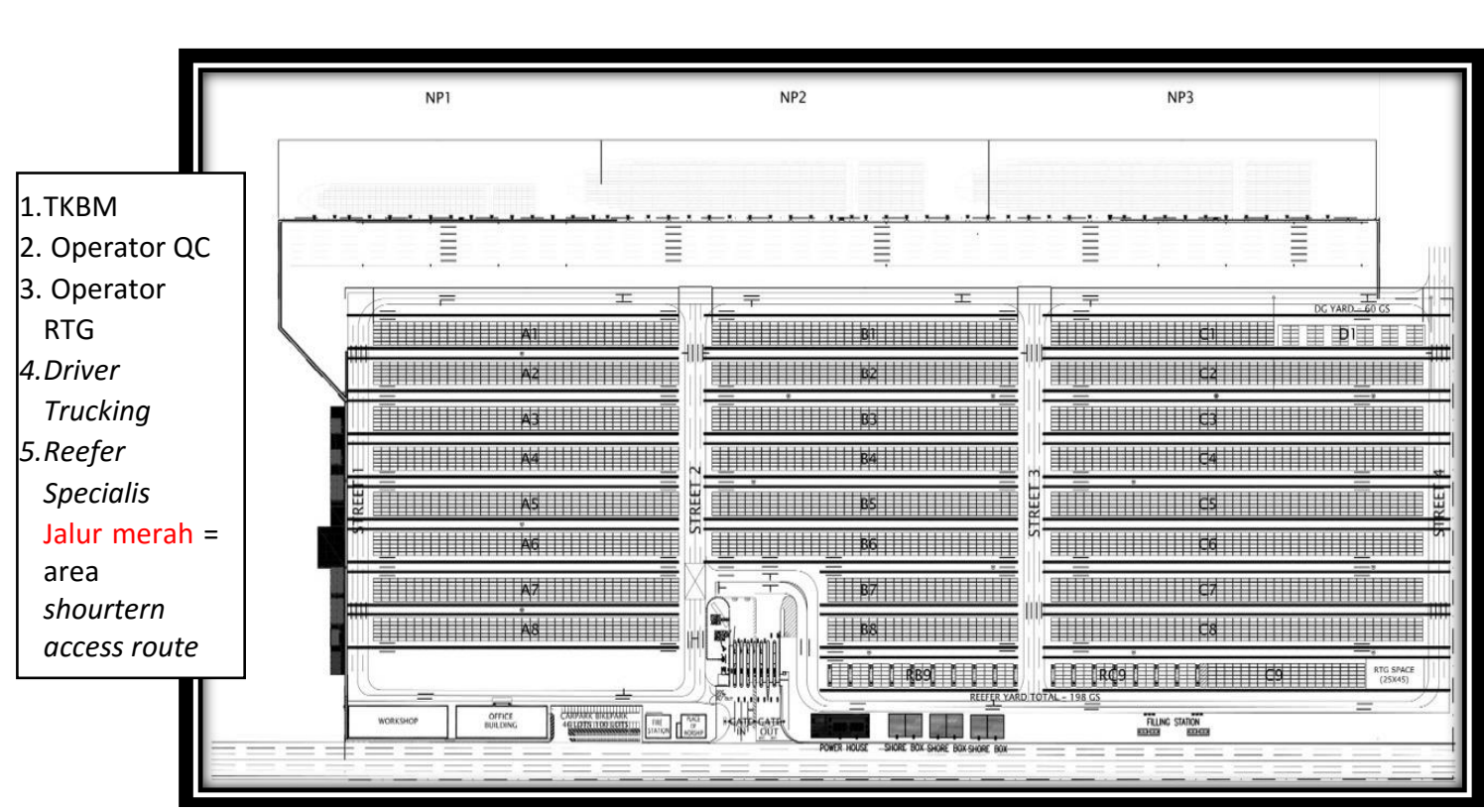

Gambar 1: Layout Area Pekerja dan Denah Lintasan Pekerja.

\section{Sumber : Diolah Peneliti}

Untuk menjamin K3, gambar di atas menunjukan area pekerja lapangan di terminal NPCT1 yang terdapat jalur merah (larangan bagi pejalan kaki) dan jalur hijau ditandai sebagai rute shuttle bus dari depan common gate sampai gate.

Pekerja yang tidak membawa kendaraan pribadi, maka menggunakan shuttle bus yang disediakan oleh NPCT1, untuk mengantarkan sampai masuk area terminal, dari gate ke area kerja masing masing. Dalam gambar ditandai dengan penomeran dari angka 1 sampai dengan 5 sesuai lokasi dengan urut sebagai berikut: 1). Pekerja TKBM di atas kapal, 2). Operator QC (Quay Crane), 3). Operator RTG (Rubber Tyred Gantry Crane), 4). Pekerja reefer specialist. 5).Driver trucking dalam terminal.

Pekerja diperbolehkan berjalan hanya di area pejalan kaki, dalam gambar penulis tandai dengan warna hijau (green line). Area pejalan kaki ditandai dari area gate sampai area workshop, artinya pejalan kaki dilarang melewati selain area tersebut. Ketentuan tersebut berlaku untuk:

a. TKBM (Tenaga Kerja Bongkar Muat) di Terminal.

b. Operator QC (Quay Crane).

c. Operator RTG (Rubber Tyred Gantry)

e. Pekerja Reefer Specialist

d. Driver Trucking.

Untuk menjamin keselamatan maka ditentukan batas kecepatan maksimal kendaraan di area terminal, dari $15 \mathrm{~km} / \mathrm{jam}, 20 \mathrm{~km} / \mathrm{jam}$ dan $45 \mathrm{~km} / \mathrm{jam}$. Pembagian ketentuan kecepatan $15 \mathrm{~km} / \mathrm{jam}$, berlaku untuk seluruh area $C Y, 20$ $\mathrm{km} / \mathrm{jam}$ di area gate in sampai area workshop, $45 \mathrm{~km} / \mathrm{jam}$ khusus area SAR (Southern Access Route), ditunjukkan dalam gambar dengan garis merah, area SAR dari depan common gate sampai dengan gate.

Bagi driver yang melanggar peraturan, maka diberi sanksi berupa peringatan/teguran untuk pelangaran ringan sampai pemecatan untuk pelanggaran 
berat. Berikut contoh gambar tanda-tanda peringatan kecepatan kendaraan di area terminal:

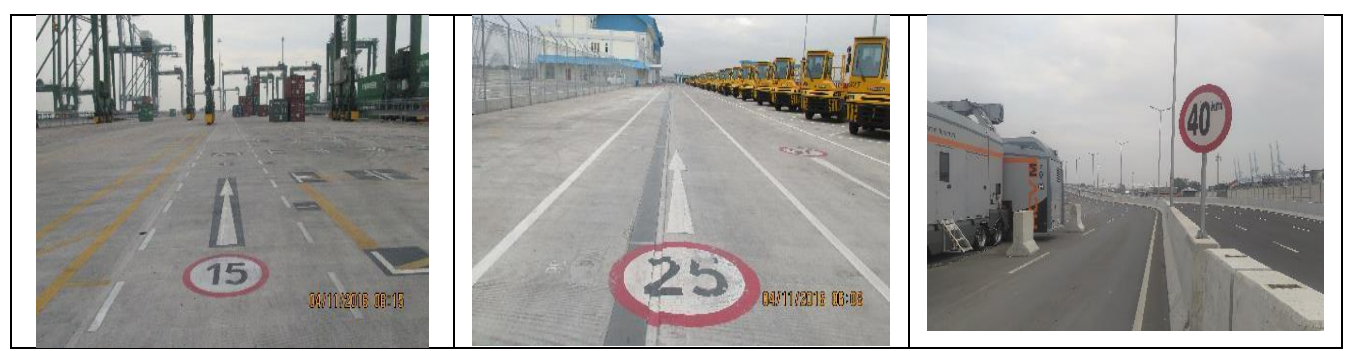

Gambar 2. Tanda Peringatan Kecepatan Kendaraan di area terminal. Sumber : NPCT1

\section{B. Bahaya, Resiko, Dampak Dan Pengendalian Resiko.}

Guna mengantisipasi bahaya dan resiko di lingkungan pelabuhan, maka dilakukan pengendalian terhadap bahaya yang ada. Beberapa cara untuk mengatasi antara lain dengan Identifikasi Bahaya, K3 dan Penilaian Resiko.

Pekerjaan memiliki tingkat bahaya, risiko serta pengendalian, penanganan yang berbeda, karena bahaya yang ada sangat komplek dan memiliki potensi resiko tinggi, seperti jatuh dari ketinggian, tertabrak alat berat/alat pengangkut.

Resiko dari bahaya yang timbul seperti patah tulang akibat terjatuh dari ketinggian, cacat sementara atau permanen bahkan dapat mengakibatkan reisiko kematian.

Berikut prosedur identifikasi bahaya, risiko dan pengendalian risiko di area terminal NPCT1 :

1. Manajer HSSE memimpin anggota komite K3 dalam mengidentifikasi bahaya $\mathrm{K} 3$ dengan mempertimbangkan:

a. Kegiatan rutin dan non-rutin.

b. Kegiatan semua personil memiliki akses ke tempat kerja termasuk kontraktor dan pengunjung. Perilaku manusia, kemampuan dan faktor manusia lainnya.

c. Mengidentifikasi bahaya yang berasal dari luar tempat kerja yang dapat berdampak buruk terhadap kesehatan dan keselamatan orang di bawah kendali organisasi.

d. Bahaya yang ditimbulkan di sekitar tempat kerja oleh aktivitas terkait pekerjaan di bawah kendali organisasi.

e. Infrastruktur, peralatan dan material di tempat kerja, disediakan oleh organisasi

f. Perubahan dalam organisasi, aktivitas atau materi.

g. Modifikasi pada sistem manajemen HSSE termasuk perubahan sementara dan dampaknya pada operasi, proses dan kegiatan.

h. Setiap kewajiban hukum yang berlaku terkait dengan penilaian risiko dan penerapan kontrol yang diperlukan.

i. Desain area kerja, proses, instalasi, mesin/peralatan, prosedur operasi dan organisasi kerja, termasuk adaptasinya terhadap kemampuan manusia. 
2. Menganalisis semua efek yang mungkin terjadi dari setiap bahaya dengan merujuk ke matriks penilaian risiko.

3. Bahaya dan efek yang teridentifikasi dicatat pada form analisis bahaya dan efek.

4. Tingkat risiko ditentukan dengan mengalikan level kemungkinan dengan level tingkat keparahan.

\section{Dokumen Identifikasi Bahaya, K3 Dan Penilaian Risiko}

Dokumen yang terkait dengan identifikasi bahaya, K3 dan penilaian risiko sbb:

1. Hazard and Effect,

Bahaya atau sumber yang menimbulkan cidera, kecelakaan atau kombinasi keduanya, ada beberapa jenis pada tiap jenis pekerjaanya. Penulis paparkan beberapa bahaya yang ada di area kerja NPCT1, lihat tabel dalam diagram bowtie pengendalian risiko.

\section{Hazard Control Sheet}

Form Hazard Control Sheet, digunakan untuk melihat informasi terkait bahaya yang ada pada tiap jenis perkerjaan di terminal. Di dalam form terdapat macam macam bahaya, sehingga pekerja mengerti bahaya pada pekerjaan masing masing dan bagaimana penanganan serta pengendalian risiko terhadap bahaya tersebut.

\section{Penilaian Bahaya dan Risiko.}

Penilaian risiko atau proses penilaian risiko dengan membandingkan tingkat/kriteria risiko yang ditetapkan untuk menentukan prioritas pengendalian bahaya yang sudah diidentifikasi.

Sistem manajemen K3 di NPCT1, menggunakan sistem dan prosedur yang tepat yang memungkinkan semua bahaya dan tempat kerja di terminal teridentifikasi dan pengendaliannya dilaksanakan secara berkelanjutan.

Berikut prosedur penilaian risiko di terminal NPCT1 :

1. Komite K3 meninjau identifikasi bahaya, efek dan kontrol setiap tahun dengan mempertimbangkan keefektifan langkah-langkah pengendalian yang ada.

2. Masing masing kepala departemen meninjau identifikasi bahaya, efek dan kontrol setiap kali terjadi insiden atau perubahan dengan berkonsultasi Departemen HSSE.

3. Melakukan investigasi pada setiap insiden yang terjadi.

4. Melakukan identifikasi bahaya terkait situasi darurat dan aktivitas non-rutin.

5. Mengelompokan sifat bahaya yang teridentifikasi, menentukan langkahlangkah pengendalian sementara, menentukan prioritas pengendalian secara permanen.

\section{E. Hierarki Pengendalian Risiko.}

Hierarki pengendalian risiko merupakan tahapan yang telah diimplementasikan untuk pengendalian, pencegahan yang dilakukan perusahaan guna menyelamatkan perusahaan dari kerugian yang bisa terjadi akibat bahaya yang ada. 


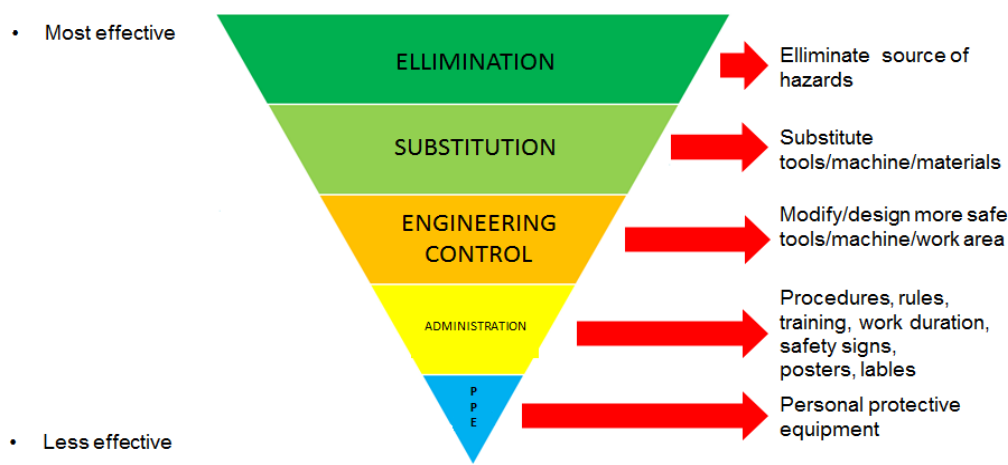

Gambar 3 : Hierarki Pengendalian Risiko. Sumber : Diklat Safety Induction NPCT1

Penilaian resiko menggunakan pendekatan metode matriks resiko yang relatif sederhana serta mudah digunakan, diterapkan dan menyajikan representasi visual di dalamnya.

Pengendalian resiko didasarkan pada hirarki sebagai berikut :

1. Eliminasi (menghilangkan sumber/aktivitas berbahaya).

2. Substitusi (mengganti sumber/ alat /mesin/bahan/material/aktivitas/area yang lebih aman).

3. Perancangan (modifikasi/instalasi sumber/alat/mesin/bahan/material/ aktivitas/area supaya menjadi aman).

4. Administrasi (penerapan prosedur/aturan kerja, pelatihan dan pengendalian visual di tempat kerja).

5. APD_(penyediaan APD_bagi tenaga kerja dengan paparan bahaya/resiko tinggi).

\section{G. Prosedur K3 Bagi Pekerja.}

Prosedur K3 merupakan tahapan dimulainya permintaan pekerjaan yang dilakukan di area terminal NPCT1. Sebelum dilakukan identifikasi bahaya yang mungkin terjadi di lapangan dan bagaimana langkah pengendalian yang dilakukan.

Selain itu dilakukan persetujuan/approval terkait suatu pekerjaan yang diajukan dan dilakukan pengecekan mengenai persiapan pemilik proses/process owner seperti perlengkapan dokumen, registrasi kesehatan dan keselamatan pekerjanya.

\section{Prosedur Kesehatan Kerja.}

Berikut gambaran prosedur kesehatan kerja sebelum pekerja melakukan pekerjaan di area terminal NPCT1 : 


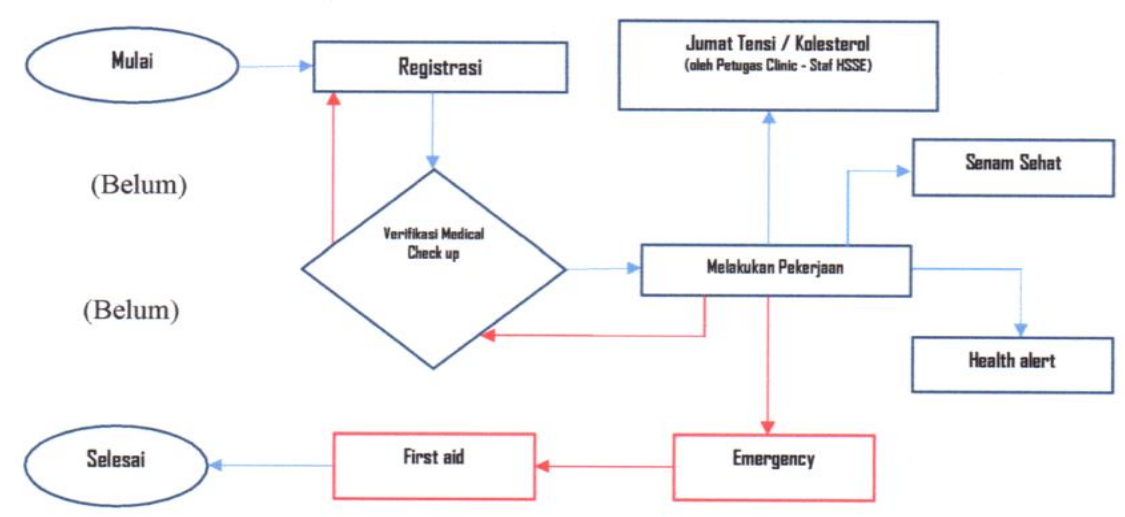

Bagan 4: Prosedur Kesehatan Kerja.

Sumber : Diolah Peneliti

Bagan 4. Merupakan flow chart prosedur kesehatan kerja di NPCT1, setiap pekerja wajib melakukan registrasi sebelum memulai pekerjaan, dilakukan pendataan medical check up, yang memenuhi persyaratan, diperbolehkan melakukan pekerjaannya. Selanjutnya dilakukan pengawasan dan pengendalian terhadap kesehatan kerja, dengan melakukan pengecekan tensi setiap minggu di hari Jumat.

a. Registrasi Kesehatan Kerja

Kegiatan registrasi bagi setiap orang yang akan melakukan pekerjaan agar mendapatkan status pekerja. Seorang pekerja memasuki area terminal, wajib melapor ke departemen HSSE, untuk dicatat sebagai daftar hadir.

b. Jum,at Tensi/Pemeriksaan Tekanan Darah

Bentuk pengawasan dan pengendalian terhadap kesehatan kerja para pekerja, secara rutin setiap hari Jum, at dilakukan pemeriksaan tensi, apabila hari Jumat libur maka dimajukan dihari sebelumnya Pemeriksaan dilakukan petugas medis oleh 1 dokter dan 1 para medis.

c. Senam Sehat

Guna mendukung kesehatan, senam merupakan salah satu kegiatan olahraga rutin setiap 2 minggu, bertujuan untuk melatih tubuh para pekerja dengan melakukan gerakan tertentu secara sengaja, sadar dan terencana, serta dilakukan secara sistematis.

Tujuan senam untuk membantu meningkatkan kebugaran jasmani, mengembangkan keterampilan, serta menanamkan nilai mental spiritual kepada para pekerja sebelum melakukan pekerjaan.

Senam dipimpin oleh 3-4 instruktur ahli yang bekerja sama dengan departemen HSSE, dilakukan ada 2 sesi dan tempat yang berbeda, pertama dilakukan di out door, khusus pekerja lapangan seperti operator, driver. Bertempat di halaman dekat Fire Station (Ruang Staf HSSE), dimulai pukul 08.00 pagi. Sesi kedua dimulai pukul 09.00 pagi sampai selesai dilakukan di Main Office Building lantai 2, diikuti oleh pekerja di dalam gedung baik karyawan maupun tenaga. 


\section{d. Health Alert}

Health Alert/peringatan kesehatan, merupakan salah satu upaya yang dilakukan oleh HSSE kepada semua pekerja terkait adanya bahaya dan risiko kesehatan yang bisa terjadi akibat bekerja di lingkungan pelabuhan. Hal ini dilakukan sebagai tindakan pencegahan, berfungsi untuk menghimbau dan mengingatkan bahaya dan risiko kesehatan bekerja di area pelabuhan.

Kegiatan dilakukan langsung seperti training safety induction oleh Tim HSSE yakni HSSE Manager, HSSE Executive, Dokter serta paramedic yang ada di Port Clinic. Health Alert dilakukan 6 bulan sekali dengan training, penerapannya secara langsung oleh HSSE Manager maupun HSSE Executive pada saat ada pekerjaan dengan bahaya tingkat risiko paling tinggi serta membutuhkan pengawasan secara konsisten oleh Tim HSSE.

\section{Prosedur Keselamatan Kerja di NPCT1}

Berikut gambaran prosedur keselamatan kerja sebelum pekerja melakukan pekerjaan di area terminal.

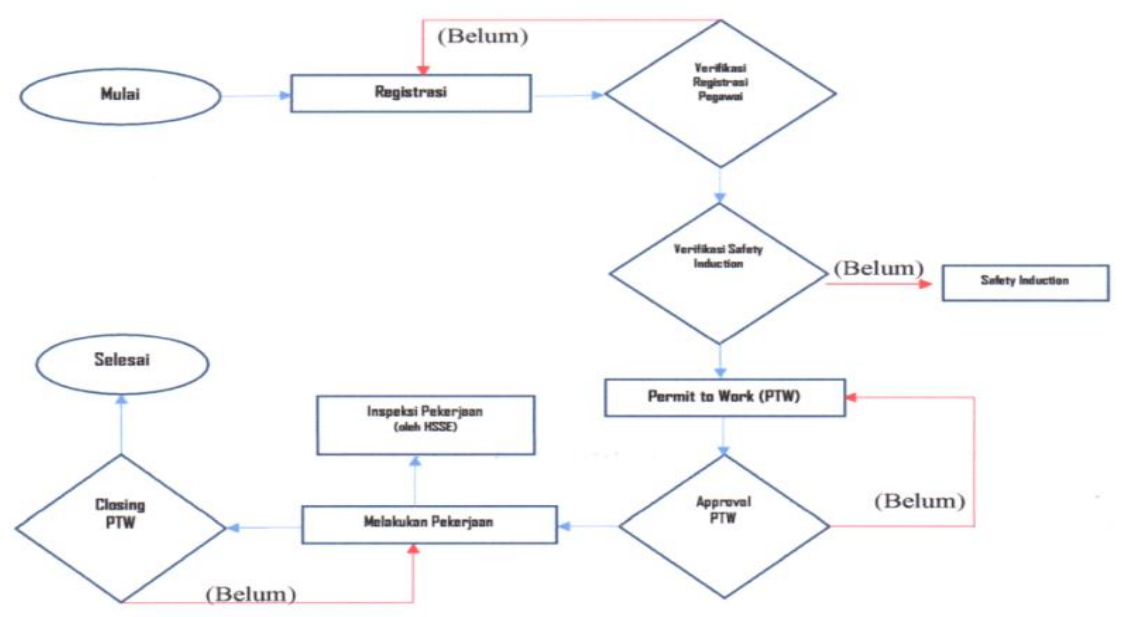

Bagan 5 : Prosedur Keselamatan Kerja.

Sumber : Diolah Peneliti

Bagan 5. Merupakan flow chart prosedur keselamatan kerja, dapat dijelaskan bahwa pekerja wajib melakukan registrasi sebelum memasuki area kerja. Setelah registrasi, semua pekerja wajib mengikuti safety induction dan melakukan pembuatan izin kerja (Permit to Work) sesuai jenis pekerjaan, kriteria pekerjaan. HSSE melakukan pemeriksaan: jenis, lokasi pekerjaan, peralatan, APD yang sesuai, prosedur kerja, kompetensi personil, penilaian dan pengendalian risiko.

Staf HSSE mengecek dan menyetujui ijin kerja, Izin kerja yang tidak disetujui, pekerja wajib melengkapi kekurangan persyaratan sesuai catatan Staf HSSE. Selama pekerjaan berjalan, pengawasan dilakukan Staf HSSE. 
Apabila pekerjaan selesai, pekerja diminta menutup izin kerjanya (permit to work), Staf HSSE melakukan pengecekan jumlah pekerja, pengecekan lingkungan. Jika dalam 4 (empat) hal tersebut di atas tidak terdapat temuan, maka izin kerja dapat ditutup, apabila terdapat masalah maka izin kerja tidak dapat ditutup.

a. Registrasi Kerja

Kegiatan registrasi kerja merupakan pendaftaran awal setiap orang yang akan melakukan pekerjaan agar mendapatkan status pekerja. Selanjutnya melakukan pelaporan kepada security, mengisi daftar hadir. Setelah terdaftar maka mendpatkan kartu identitas pekerja. Kartu identitas tersebut digunakan untuk akses masuk ke area kerja.

b. Safety Induction

Safety Induction merupakan pelatihan pengenalan dasar keselamatan di area kerja oleh Staf HSSE. Tujuannya untuk sosialisasi peraturan yang ada, seperti peraturan lalu lintas, pejalan kaki, pengetahuan mengenai bahaya dan risiko kerja, penilaian risiko dan pengendalian risiko.

c. Izin Kerja (Permit to Work/PTW)

Izin Kerja merupakan sarana komunikasi yang efektif antara manajemen, supervisor dan operator, mereka yang melakukan pekerjaan di area berbahaya atau pekerjaan berbahaya.

Prosedur permit to work berlaku untuk semua karyawan dan kontraktor yang ditugaskan oleh Supervisor untuk melakukan pekerjaan di area berbahaya, atau pekerjaan berbahaya yang berdampak buruk terhadap keselamatan manusia, lingkungan, reputasi, dan keuangan perusahaan.

Ijin Kerja dilengkapi dengan dokumen pendukung seperti JSA (Job Safety Analysis) dan Safety Tool Box.

d. Ijin Kerja Dingin (Cold Work Permit)).

Ijin kerja untuk pekerjaan seperti: Hidro test, Phenuematic test, Pengecatan, pekerjaan Sipil dll.

e. Ijin Kerja Masuk Ruang Terbatas (Confined Space Entry Permit).

Ijin kerja untuk bekerja di dalam ruang terbatas, yang dimaksud terbatas :

1) Kemungkinan dari keterbatasan oksigen di dalam ruang kerja.

2) Ruangan bekas dari bahan kimia dan gas lain.

3) Akses masuk/keluar tempat kerja yang terbatas.

4) Pencahayaan kurang serta pekerjaan seperti bekerja di dalam tangki.

f. Ijin Kerja Listrik (Isolation Work Permit), merupakan ijin kerja untuk pekerjaan menghidupkan atau perbaikan peralatan listrik baru atau peralatan lama dan battery charging.

g. Ijin bekerja diatas ketinggian (Working at Height), ijin kerja yang diberikan kepada pekerja yang bekerja di atas ketinggian, dimana akses ketempat kerja harus menggunakan personal basket (tanpa tangga/ladder).

h. Safety Tool Box

Safety Tool Box merupakan forum diskusi pengarahan kerja yang dipresentasikan oleh supervisor sekitar 10-20 menit seperti prosedur, risk assesment dan identifikasi bahaya dan penanggulangan apabila terjadi keadaan darurat. 


\section{Pemeriksaan Keselamatan/Safety Inspection}

Safety Inspection atau kegiatan inspeksi dengan melakukan keliling disetiap area untuk memastikan tidak ada tindakan/keadaan tidak aman, sapabila terdapat temuan maka dibuat laporan dan dipresentasikan dalam rapat mingguan manajemen.

Kegiatan safety inspection dilakukan oleh tim pemilik proses kerja dan diawasi oleh Staf HSSE, dilakukan 3 orang, apabila ada temuan maka didiskusikan. Kegiatan Safety Inspection dilakukan Staf HSSE mulai dari gate sampai seluruh area terminal, termasuk kapal sandar melakukan bongkar muat di dermaga.

a. Gate.

Kegiatan safety inspection dilakukan pada area berikut :

Pemeriksaan di gate dilakukan dengan memeriksa langsung semua kendaraan yang masuk, dengan mencatat identitas driver, nomor polisi kendaraan dan barang yang diangkut.

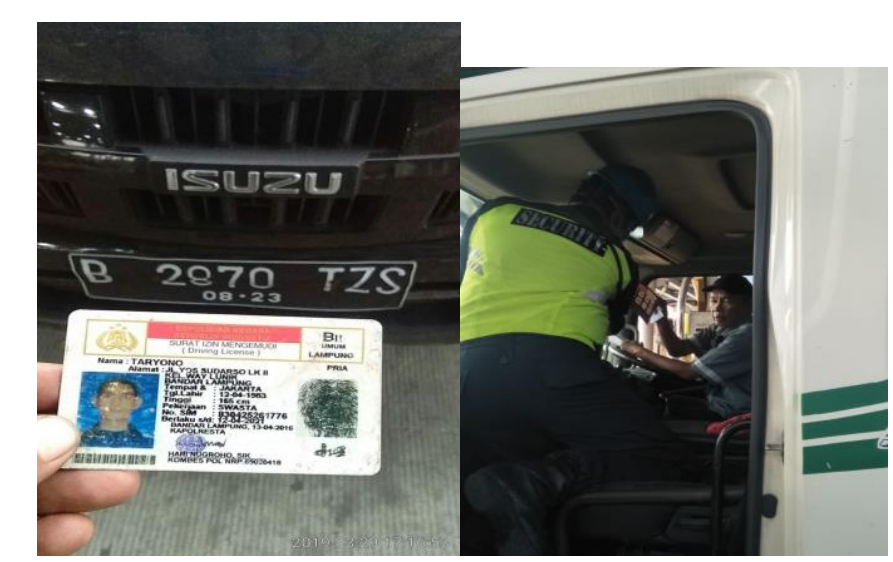

Gambar 6: Safety and Security Inspection in gate.

Sumber : Dokumentasi Peneliti.

\section{b. Gas Room}

Gas Room atau ruangan penyimpanan gas untuk keperluan memasak di dapur kantin terminal. Safety Inspection di area gas room ini dengan alat gas detector yang dilakukan oleh petugas kantin dan dilakukan pengawasan Staf HSSE.

c. Instalasi Pengolahan Air Limbah

Instalasi Pengolahan Air Limbah (IPAL) merupakan tempat pengolahan air limbah yang dihasilkan dari limbah domestic, bersumber dari gedung gegung. diolah menjadi air limbah sesuai ambang batas yang dipersyaratkan sebelum dibuang ke laut sehingga tidak menimbulkan pencemaran.

Inspeksi K3 dan Lingkungan dilakukan di area IPAL untuk memastikan tidak ada kebocoran pipa saluran air dan bak penampungan IPAL serta tidak ada kerusakan mesin pengolahan air limbah, untuk menjamin keamanan lingkungan. 


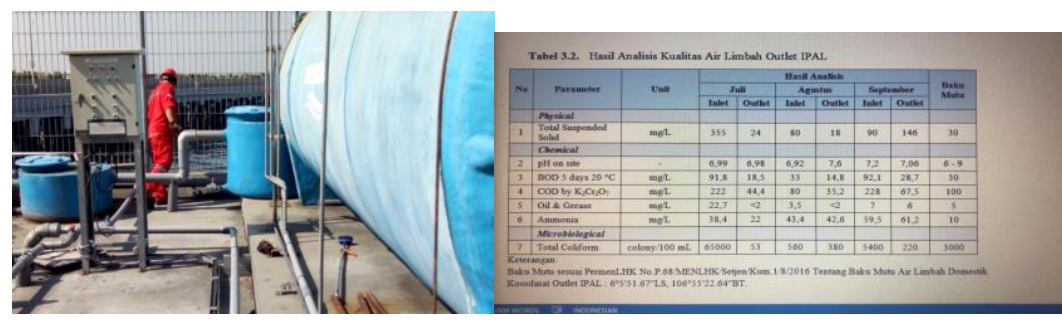

Gambar 7: Safety Inspection di area IPAL dan daftar ambang batas. Sumber: NPCT1

\section{d. Storage Limbah B3}

Storage digunakan untuk menyimpan limbah B3. Dilakukan pengecekan tabung tabung limbah B3 untuk memastikan tidak ada kebocoran di area storage yang dapat mengakibatkan pencemaran lingkungan.

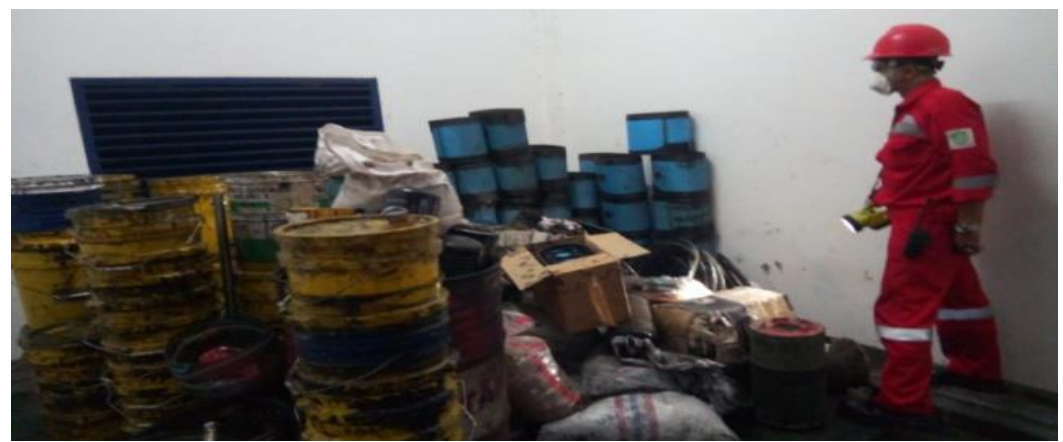

Gambar 8: Safety Inspection di Storage Limbah B3

Sumber : Dokumentasi Peneliti

e. Dermaga.

Safety Inspection yang dilakukan pada dermaga terkait aktivitas kapal nelayan lokal di sekitar dermaga NPCT1, untuk memastikan pergerakan kapal nelayan lokal tidak mengganggu kapal sandar yang sedang melakukan bongkar muat.

Selain pemeriksaan aktivitas kapal nelayan lokal, Staf HSSE juga melakukan pemeriksaan pada jaring penolong yang ada di dermaga untuk memastikan tali berada di dalam kotak jaring penolong dan semua pengikat pada tali dalam keadaan baik.

f. Container Yard Dangerous Goods (DG).

Container Yard Dangerous Goods (DG) merupakan blok khusus untuk kontainer berbahaya dan beracun (DG) yang berada di blok C.01. Safety Inspection di area Container Yard DG meliputi pemeriksaan susunan container DG (tidak boleh lebih dari 2 tier), kebocoran container DG dan pengecekan Eye Wash (tempat cuci mata setelah petugas melakukan pemeriksaan di area container DG). 


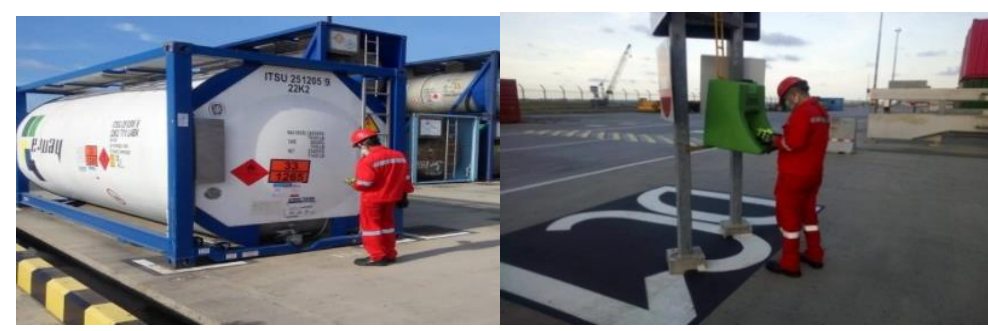

Gambar 9: Safety Inspectin Container DG

Sumber : Dokumentasi Peneliti.

\section{g. Vessel Inspection}

Vessel Inpection /pemeriksaan kapal guna memastikan pekerja TKBM bekerja sesuai prosedur, menjaga kebersihan lingkungan di kapal dan sekitar dermaga. Memeriksa kapal sandar dengan baik, tidak membuang limbah ke laut yang dapat mengakibatkan pencemaran lingkungan.

Pemeriksaan meliputi:

1). Pengawasan Penambatan Tali Kapal/Vessel Mooring Monitoring.

Melakukan pemantauan dan pengawasan pekerja mooring kapal memasang tali saat kapal sandar di dermaga, memastikan posisi kapal sandar berada pada posisi aman dan selamat, tidak berpotensi bahaya pergerakan kapal saat mooring. Pekerja mooring menggunakan life jacket, tidak ada ancaman keamanan.

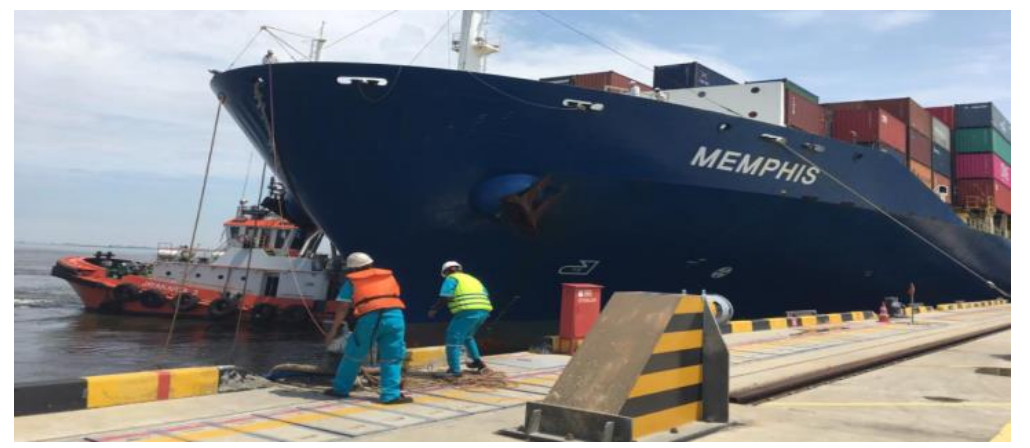

Gambar 10: Vessel Mooring Monitoring

Sumber : Dokumentasi Peneliti.

\section{2). Pengarahan, Peregangan sebelum TKBM Kerja/Briefing and Stretching} Lashing Man

Melakukan pengarahan kepada TKBM terkait keselamatan dan keamanan kerja bongkar muat, sebelumnya melakukan stretching /pemanasan sebelum bekerja. Memperhatikan penggunaan APD, tidak berada dalam line of fire.

3). Pengawasan Pergerakan Truk Pemindah Kontainer (PM) dengan metode "Stop and Go"/ Haulage Monitoring.

Pengawasan dilakukan terkait kegiatan coneman saat kegiatan pengangkutan kontainer menggunakan trucking/PM dari kapal ke CY dan sebaliknya. Memastikan trucking PM berhenti sesuai tempat yang ditandai safety cone, 
trucking PM dilarang berjalan apabila safety cone masih terpasang dan kegiatan bongkar muat masih berlangsung.

4). Pemeriksaan di Kapal/Vessel Inspection

Patroli K3, keamanan dan lingkungan di kapal untuk memastikan pekerja TKBM bekerja sesuai prosedur yang aman, menjaga kebersihan lingkungan di kapal dan sekitar dermaga dan TKBM telah mengunci muatan dengan twist lock secara benar.

5). Pengawasan Pelepasan Tali Kapal/Vessel Un-Mooring Monitoring

Melakukan pemantauan dan pengawasan terkait pekerja mooring ketika melepas tali kapal saat kapal hendak lepas sandar dari dermaga.

Pengecekan pekerja mooring menggunakan APD sesuai prosedur.

6). Pengawasan Kapal Lepas Sandar/Vessel Un-berthing Monitoring.

Melakukan pemantauan dan pengawasan pergerakan kapal yang keluar untuk lepas sandar dari dermaga, memantau pergerakan kapal saat di pandu dengan aman dan selamat.

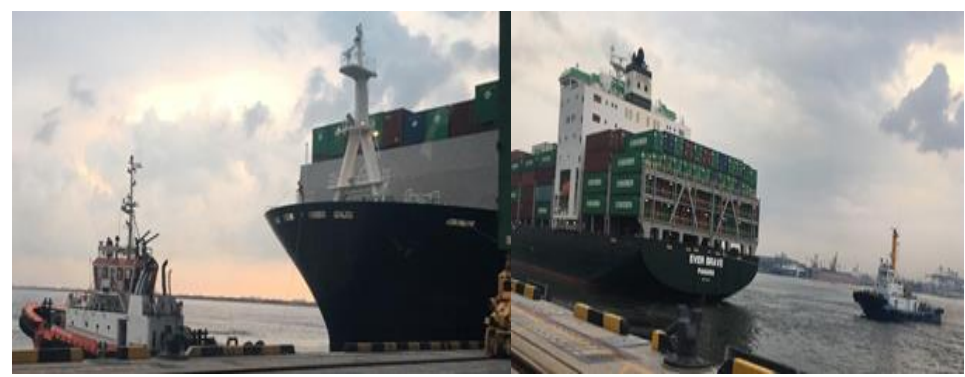

Gambar 11: Vessel Un-berthing Monitoring

Sumber : Dokumentasi Peneliti.

Hambatan kegiatan safety inspection atau pemeriksaan keselamatan terjadi seperti jadwal bersamaan dengan Port tour dari kunjungan manajemen yang masuk ke area NPCT1, yang mendadak/sidak. HSSE sebagai penanggung jawab keselamatan kerja perlu mendampingi Port tour dalam pemeriksaan selesai dan pengunjung keluar dari gate NPCT1.

Selanjutnya melaporkan temuan (finding report) yang didapat tentang kondisi tidak aman, nyaris celaka, budaya atau perilaku HSSE positif yang diamati oleh siapapun di lingkungan kerja.

Laporan temuan, penemu unsafe condition maupun unsafe action yang ada di area terminal, melaporkan melalui whatsapp aplikasi, dengan cara memotret keadaan maupun tindakan tidak aman dan memberikan informasi terkait kejadian dan mengirimkan ke nomer darurat/emergency call.

7). Tindakan Penanggulangan dan Upaya Pertolongan/Prevention Action and Rescue Effort.

Berikut upaya dan tindakan penanggulangan keselamatan dan upaya pertolongan pada korban (pekerja) saat terjadi kecelakaan kerja dengan cara:

1). Simulasi Keselamatan/Safety Drill

Simulasi keselamatan dilakukan sesuai jadwal dan rencana kegiatan

HSSE, setiap 3 bulan sekali, dengan tujuan pekerja memahami apa yang 
harus dilakukan apabila terjadi keadaan darurat/emergency cases. Seperti simulasi gempa bumi, simulasi pekerja mengalami keram saat bekerja di ketinggian.

Simulasi bencana alam/gempa bumi, pekerja berusaha berlindung dengan prinsip three angle of life (di bawah meja) sekitar 2-3 menit, setelah itu keluar melalui jalur emergency mengikuti koordinator di area kerja menuju ke mustar station (titik berkumpul). Tujuan drill dilakukan agar setiap pekerja baik karyawan maupun kontraktor lebih mengenal dan mengetahui apa yang harus dilakukan jika benar-benar terjadi gempa bumi, dan mengetahui tempat titik kumpul untuk evakuai.

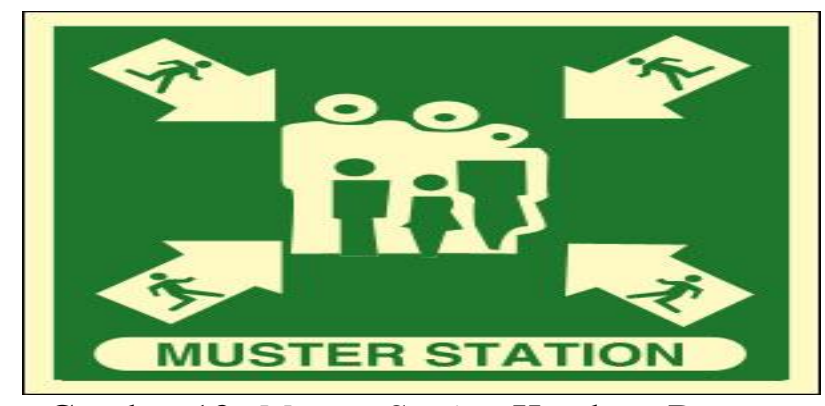

Gambar 12: Muster Station Keadaan Darurat

Sumber : NPCT1

2). Latihan Pemadaman Kebakaran/Fire Rescue Exercise

Fire Rescue Exercise di area terminal dilakukan Staf HSSE (Emergency Response Team dan Security Guard). Kegiatan latihan dilakukan secara konsisten oleh Staf HSSE setiap shift 2 dan 3. Target HSSE proses fire rescue maksimal 8 menit dari mulai Staf HSSE mengenakan fireman outfit sampai roll on- roll off selang air dari fire truck dan melakukan pemadaman di area objek kebakaran.

3). Penyelamatan Korban dari Ketinggian/Vertical Rescue Exercise

Vertical Rescue Exercise dilakukan Staf HSSE (Emergency Response Team dan Paramedic), untuk menanggulangi apabila terjadi pekerja di ketinggian seperti operator RTG, operator QC dan pekerja lain yang berada di ketinggian mengalami kejadian darurat di area kerja.

Target pelaksanaan 11menit mulai Staf HSSE memakai vertical rescue equipment seperti body harness, caribiner, menyiapkan tali sampai menuju ke lokasi tempat korban, dengan menaiki ketinggian, memasang perlengkapan dan menempatkan korban di tandu dengan semua perlengkapan sudah terpasang oleh penolong di korban, lalu korban dan penolong turun bersamaan dari ketinggian area kerja korban.

4). Penyelamatan Korban di Laut/Rescue Boat Exercise

Rescue Boat Exercise dilakukan oleh Staf HSSE (Emergency Response Team dan Paramedic) untuk menyelamatkan pekerja yang terjatuh di laut dengan menggunakan boat atau perahu karet, untuk menjangkau penolong menuju ke tempat korban berada. 
Apabila korban sudah terjangkau selanjutnya di naikan ke dalam boat bersama penolong, setelah semua perlengkapan rescue terpasang dengan korban lalu boat diangkat kembali menuju atas demaga/jetty menggunakan quay crane.

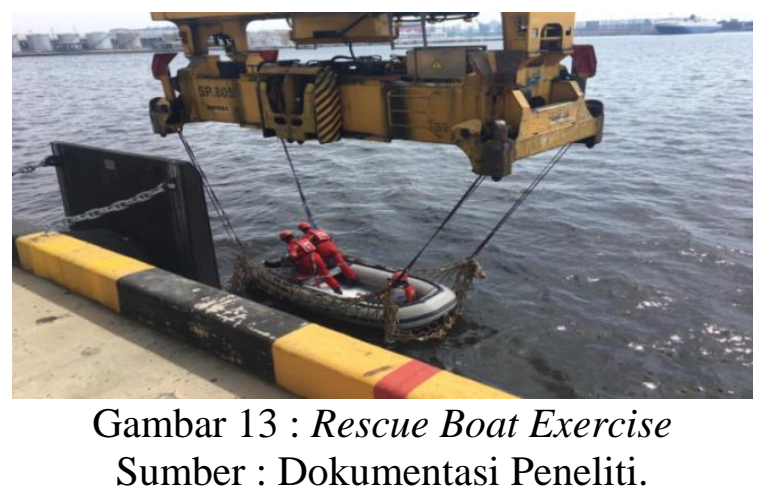

Semua kegiatan penerapan K3 dilakukan sesuai standart peraturan yang berlaku, sehingga samapai penulis selesai penelitian tidak terjadi kecelakaan.

\section{PENUTUP}

Pelabuhan New Priok Container Terminal One (NPCT1) menangani lebih dari setengah volume total Indonesia, yang menjadi kelebihan beban selama bertahun-tahun. Pengembangan New Priok menjadikan fasilitas pelabuhan Jakarta sejajar dengan pelabuhan kelas dunia lainnya dan memberikan peluang konektivitas jaringan baru ke jalur pelayaran. Secara signifikan memperkuat daya saing rantai logistik Indonesia dan mengarah pada lingkungan perdagangan yang lebih baik.

NPCT1 merupakan terminal pertama pengembangan New Priok Indonesia dan diposisikan untuk menyediakan layanan pelabuhan terbaik di kelasnya bagi pelanggan, mitra dan pemangku kepentingan.

Dengan standar Kesehatan Dan Keselamatan Kerja (K3) dan keamanan lingkungan di pelabuhan yang sangat baik, NPCT1 menjadi kiblat pelabuhan internasional terbaik di Indonesia. Aspek keselamatan dan kesehatan kerja di NPCT1 menjadikan pelabuhan ini berbeda dengan pelabuhan lain di Indonesia.

Karena ketertiban dan konsistennya dalam penerapan K3 di NPCT1 maka dalam kurun waktu 3 (tiga) tahun berturut-turut, mulai dari 18 Agustus 2016 sampai 18 Agustus 2019, tidak terjadi kecelakaan (Zero Accident), sehingga pihak Pengelola Pelabuhan/Port Authority Tanjung Priok memberikan apresiasi Penghargaan Kecelakaan Nihil berupa Zero Accident Award kepada NPCT1.

K3 dan Keamanan di NPCT1 dilakukan dengan sangat ketat dan konsisten sehingga semua berjalan sesuai ketentukan. K3 dilaksanakan oleh Staf HSSE langsung, dengan jumlah personil 16 (enam belas) orang Staf HSSE, terbagi menjadi 4 regu, setiap regu memiliki 1 (satu) orang admin, 1 (satu) orang Danru dan 2 (dua) orang anggota.

Namun kinerja dari Staf HSSE NPCT1 sangat baik dan professional, sehimgga dapat melaksanakan Port Patrol Inspection setiap 1 (satu) jam sekali setiap hari, dengan diklat yang rutin dan konsisten seperti latihan pemadaman 
kebakaran (fire rescue) dengan target 8 (delapan) menit setiap latihan, latihan vertical rescue dengan target 11 (sebelas) menit setiap latihan, serta memiliki quick response sangat baik.

NPCT1 memiliki Port Clinic yang digunakan sebagai tempat layanan gangguan kesehatan bagi para pekerja baik karyawan maupun kontraktor. Port Clinic dijaga oleh 2 (dua) orang dokter dan 4 (empat) paramedic, dengan jadwal 1 (satu) dokter bertugas pada Senin - Jumat pada pukul 08.00 sampai 17.00 dan 1 (satu) dokter lainnya bertugas pada hari Sabtu - Minggu pada jam yang sama, sedang paramedic yang bertugas jaga terbagi shift.

\section{DAFTAR PUSTAKA}

Antão, P., Calderón, M., Puig, M., Michail, A., Wooldridge, C., \& Darbra, R. M. (2016). Identification of occupational health, safety, security (OHSS) and environmental performance indicators in port areas. Safety Science, 85, 266275.

Irzal, M. K. (2016). Dasar-Dasar Kesehatan dan Keselamatan Kerja: Edisi 1. Kencana.

Undang-Undang No. 13 Tahun 2003, Tentang Ketenagakerjaan.

Levy, B. S., \& Wegman, D. H. (2000). Occupational health: recognizing and preventing work-related disease and injury. Lippincott Williams \& Wilkins,.

Manulang, S. H. (1987). Pokok-Pokok Ketenagakerjaan Indonesia. Penebit Rineka Cipta, Jakarta.

Mardalis. (2010). Metode Penelitian. Bumi Aksara.

Narbuko. (2005). Metodologi Penelitian. Bumi Aksara.

Sistem Manajemen Keselamatan Dan Kesehatan Kerja, (2007).

Peraturan Pemerintah Republik Indosesia No. 21 Tahun 2010 Tentang Perlindungan Lingkungan Maritim.

Roqib Muhammad. (2008). Kasus Kecelakaan Kerja di Tanjung Perak Tinggi. Okezone.Com.

Standard, A. (1990). Workplace injury and disease recording standard AS 1885.11990. Australian Standard, North Sydney, 28.

Suma'mur. (1981). Keselamatan Kerja dan Pencegahan Kecelakaan,. PT. Gunung Agung.

Undang Undang No. 1 Tahun 1970, Tentang Keselamatan Kerja, (1970). 